\title{
Electrochemical performance of tin-based nano-composite electrodes using a vinylene carbonate-containing electrolyte for Li-ion cells
}

\author{
G. Kilibarda ${ }^{\text {a,b,* }}$, S. Schlabach ${ }^{\text {a }}$, V. Winkler ${ }^{\text {a,b }}$, M. Bruns ${ }^{\text {a,c }}$, T. Hanemann ${ }^{\text {a,b }}$, D.V. Szabóa \\ ${ }^{a}$ Karlsruhe Institute of Technology, Institute for Applied Materials, Germany \\ ${ }^{\mathrm{b}}$ University of Freiburg, Department of Microsystems Engineering, Germany \\ ${ }^{\mathrm{c}}$ Karlsruhe Institute of Technology, Karlsruhe Nano Micro Facility, Germany
}

H I G H L I G H T S

- Synthesis of tin based hydrocarbon nanoparticulate composite electrodes.

- Vinylene carbonate in the electrolyte improves the electrochemical performance.

- A polymeric SEI, detected by XPS, is the reason for the improvement.

- The evolution of reactions occurring during cycling are traced by XRD.

- An explanation for different cycling behavior at varying current density and temperature is presented.

Keywords:

Li-ion cell

Sn nanocomposite electrode

Temperature

Current density

Vinylene carbonate (VC)

SEI-formation

\begin{abstract}
A B S T R A C T
Tin represents a promising material to increase the specific capacity compared to the state of the art graphite anodes in lithium ion cells. The aim of this work is to explain the electrochemical behavior of tin based hydrocarbon nanoparticulate composite electrodes, synthesized by means of a microwave plasma technique without any binder or slurry process. A comprehensive electrochemical character ization shows that adding vinylene carbonate (VC) to the electrolyte improves the electrochemical performance. Electrochemical impedance spectroscopy (EIS) and post mortem investigations of the cycled electrode material by X ray photoelectron spectroscopy (XPS) reveal the formation of a polymeric SEI during the first cycles, being responsible for the improvement. The differential capacity plots of the discharging process show that the lithium richest phase $\left(\mathrm{Li}_{22} \mathrm{Sn}_{5}\right)$ is formed during electrochemical loading. A comprehensive characterization with specially designed electrochemical tests finally dem onstrates the decrease of capacity with increasing temperature. This is due to intensified mechanical stresses and a fresh SEI formation. Due to destruction of the electrode material degradation is also observed with increasing current density. The SEI layer on the surface of the electrodes is confirmed by scanning electron microscopy (SEM) investigations and energy dispersive $\mathrm{X}$ ray spectroscopy (EDS) elemental mapping.
\end{abstract}

\section{Introduction}

Owing to their high energy density, long cycle life and envi ronmental safety characteristics, lithium ion cells have taken the most important role in the energy storage. Graphite anodes are

\footnotetext{
* Corresponding author: Goran Kilibarda, KIT, Hermann-von-Helmholtz-Platz 1 76344 Eggenstein-Leopoldshafen, Germany. Tel.: +49 72160823702. E-mail address: goran.kilibarda@kit.edu (G. Kilibarda).
}

currently state of the art in lithium ion cells with a specific capacity of $372 \mathrm{mAh} \mathrm{g}^{-1}$. The demand for materials with higher capacity increases and so today's research is still in search of useful material systems to replace graphite as anode in Li ion cells. Tin based materials represent such a promising material [1-3], with a theo retical specific capacity of $994 \mathrm{mAh} \mathrm{g}^{-1}$ for metallic Sn. Addition ally, carbonaceous materials like hydrocarbons, $\mathrm{C}_{x} \mathrm{H}_{y}$, have been reported [4-11], characterized by a specific capacity depending on the $\mathrm{H} / \mathrm{C}$ ratio. Values of up to $800 \mathrm{mAh} \mathrm{g}^{-1}$ are commonly reported. Chen et al. [9] are finding specific capacities of about $3400 \mathrm{mAh} \mathrm{g}^{-1}$, and Fey et al. [10] even report a specific capacity around 
$4765 \mathrm{mAh} \mathrm{g}^{-1}$. Because the tin based materials suffer from a huge volume change during cycling and, therefore, a degradation of the specific capacity, the challenge is to keep the promising initial ca pacities constant for many cycles. The aim of this work is to improve the cyclic stability by targeted materials design. Our approach is to use nanoparticulate composites. We expect such materials to benefit from the nanoporous morphology, featuring locally free space to compensate volume changes during the charging/discharging process, as it was reported elsewhere [1216]. The targeted synthesis of a nanoparticulate composite mate rial like tin-hydrocarbon should minimize the degradation, as the hydrocarbon can act as a buffering system and also contribute itself to the whole capacity of the composite. Additionally, the additive VC in the electrolyte is able to form an SEI layer, which is more stable comparing to the standard electrolyte without additives. This enhancement of the SEI can also minimize the already mentioned degradation of specific capacity.

The electrochemical investigation was performed on nano particulate electrode material, synthesized by means of the Karls ruhe Microwave Plasma Process (KMPP) [17] and deposited onto the Ni current collector directly out of the KMPP particle stream. To investigate the electrochemical performance tailored tests were designed, addressing the main parameters temperature and cur rent density, as well as the additive vinylene carbonate (VC) to the electrolyte. Complementary chemical post mortem analysis were performed by X ray diffraction (XRD) and X ray photoelectron spectroscopy (XPS) to investigate several reaction steps taking place in the discharging process with respect to the chemical composition of electrode surfaces. These studies are complemented by scanning electron microscopy (SEM) and energy dispersive $\mathrm{X}$ ray spectroscopy (EDS) to get information on the morphology and element distribution as well.

\section{Experimental}

\subsection{Electrode synthesis and material characterization}

The Karlsruhe Microwave Plasma Process was used for the synthesis of electrodes. The principles of the process are described elsewhere [17]. Water free tetra $n$ butyltin, $\mathrm{Sn}\left(\mathrm{C}_{4} \mathrm{H}_{9}\right)_{4},(94 \%, \mathrm{ABCR}$, Karlsruhe, Germany) was used as a precursor with a feeding rate of $5 \mathrm{ml} \mathrm{h}^{-1}$ and pure $\operatorname{Ar}(99,9999 \%$, Air Liquide, Düsseldorf, Germany) with a gas flow rate of $51 \mathrm{~min}^{-1}$ as carrier gas. The power of the microwave was set to $700 \mathrm{~W}$ and the system pressure to $12 \mathrm{mbar}$. These special parameters are expected to yield in nano composite material consisting of tin based particles combined with hydro carbons, $\mathrm{C}_{x} \mathrm{H}_{y}$, stemming from the organic precursor. The presence of the hydrocarbons was shown in previous work [18] using the same organometallic precursor, but $\mathrm{Ar}-\mathrm{O}_{2}$ gas mixture as reaction and carrier gas, yielding in a $\mathrm{SnO}_{2}-\mathrm{C}_{x} \mathrm{H}_{y}$ nanocomposite.

The resulting composite particles were deposited as a porous nanoparticle film onto $300{ }^{\circ} \mathrm{C}$ preheated Nickel current collector substrates, showing good adhesion onto the collector. Thus, addi tional slurry systems in combination with carbon black or binder are not necessary. Besides the deposition, powder of the composite material was collected by thermophoresis for further character ization. The weight ratios of the composite material were investi gated by thermogravimetric analyses coupled with differential scanning calorimetry (TGA-DSC) on a Jupiter STA 449C (Netzsch, Selb, Germany). The samples were treated in synthetic air with a heating rate of $5 \mathrm{~K} \mathrm{~min}^{-1}$ from RT to $1000^{\circ} \mathrm{C}$. The material shows a weight ratio of $65 \mathrm{wt} \% \mathrm{Sn}$ and $35 \mathrm{wt} \%$ hydrocarbons. The H/C ratio of the composite material was investigated by $\mathrm{HCN}$ analyses on an elemental analyzer for microsamples, LECO CHNS 932 (LECO, Mönchengladbach, Germany). The $\mathrm{H} / \mathrm{C}$ ratio, including a correction of water content of $2 \mathrm{wt} \%$ (TGA-DSC at $150{ }^{\circ} \mathrm{C}$ ) was measured to be around 1.6.

\subsection{Cell assembling}

All electrodes were assembled as Swagelok type half cells in an argon filled Unilab glove box (MBraun, Garching, Germany). To reduce moisture, stemming potentially from the synthesis itself and the sample electrode transport into the glove box, respectively, all electrodes were dried in a vacuum oven (Vakucenter VC20, Salvis Lab, Rotkreuz, Germany) for $2 \mathrm{~h}$ at $140{ }^{\circ} \mathrm{C}$. A glass fiber (Whatman, Maidstone, England) was used as separator, and lithium foil (Alfa Aesar, Ward Hill, USA) as counter and reference electrode. Two different electrolytes were used. The first electrolyte is a commercially available solution of $1 \mathrm{M} \mathrm{LiPF}_{6}$ in ethylene carbonate (EC) and dimethyl carbonate (DMC) (50:50) and was obtained from Merck (LP 30, Merck, Darmstadt, Germany). For the second elec trolyte, vinylene carbonate (VC) (97\%, Sigma Aldrich, St. Louis, USA) was added to the commercial electrolyte. This resulted in a composition of $1 \mathrm{M} \mathrm{LiPF}_{6}$ in EC, DMC and VC (45:45:10). Prior to the cycling tests all cells were stored for $24 \mathrm{~h}$ after assembling to ensure complete wetting of the electrode.

\subsection{Electrochemical performance}

All electrochemical tests were performed using a Lithium cell cycler (LICCY, KIT, IPE, Germany) in a voltage range between 0.1 and $2.8 \mathrm{~V}$ vs. $\mathrm{Li} / \mathrm{Li}^{+}$. Additionally, electrochemical impedance spectros copy (EIS) was carried out on a Zahner Zennium (Zahner Elektrik, Kronach, Germany) to investigate selected electrochemical re actions in more detail, in particular the SEI formation. For these investigations cells were discharged down to $0.1 \mathrm{~V}$ prior to EIS. The frequency used for the impedance measurements was in the range of $100 \mathrm{kHz}$ to $10 \mathrm{mHz}$ and the signal amplitude was set to $5 \mathrm{mV}$.

Current density and temperature were varied in order to investigate the electrochemical performance of the cells in different environmental conditions. The temperature variation was done by placing the respective half cells either in a reasonable air conditioned room (RT), into a drying oven (Heraeus T6060, Thermo Electron LED, Langenselbold, Germany), or into a modified conventional refrigerator. Details of the different experimental parameters are summarized in Table 1.

Table 1

Investigated half-cells and the corresponding information concerning electrochemical characterization.

\begin{tabular}{|c|c|c|c|c|c|}
\hline Cell & Electrolyte & $\begin{array}{l}\text { Active } \\
\text { mass } \\
(\mathrm{mg})\end{array}$ & $\begin{array}{l}\text { Temperature } \\
\text { (number of cycles) }\end{array}$ & $\begin{array}{l}\text { Current density } \\
{\left[\mathrm{mA} \mathrm{g}^{1}\right]} \\
\text { (number of cycles) }\end{array}$ & $\begin{array}{l}\text { EIS, after } \\
\text { discharge } \\
\text { cycle }\end{array}$ \\
\hline a & LP30 & 0.2 & RT (50) & $41(50)$ & \\
\hline b & LP30 + VC & 0.3 & RT (50) & $41(50)$ & \\
\hline c & LP30 & 0.5 & RT (3) & $41(3)$ & $1 ; 2 ; 3$ \\
\hline d & $\mathrm{LP} 30+\mathrm{VC}$ & 0.3 & RT (3) & $41(3)$ & $1 ; 2 ; 3$ \\
\hline e & $\mathrm{LP} 30+\mathrm{VC}$ & 0.3 & RT (60) & $\begin{array}{l}41(15) \\
82(10) \\
164(10) \\
821(10) \\
41(15)\end{array}$ & \\
\hline $\mathrm{f}$ & $\mathrm{LP} 30+\mathrm{VC}$ & 0.3 & $\begin{array}{l}\text { RT (11) } \\
40^{\circ} \mathrm{C}(10) \\
\mathrm{RT}(12) \\
5^{\circ} \mathrm{C}(9) \\
\mathrm{RT}(8)\end{array}$ & $41(50)$ & \\
\hline g & $\mathrm{LP} 30+\mathrm{VC}$ & 0.2 & $\begin{array}{l}\text { RT (3) } \\
40^{\circ} \mathrm{C}(1)\end{array}$ & $41(4)$ & $2 ; 3 ; 4$ \\
\hline $\mathrm{h}$ & $\mathrm{LP} 30+\mathrm{VC}$ & 0.8 & $\mathrm{RT}(0.5 ; 2.8 \mathrm{~V} \quad 0.8 \mathrm{~V})$ & $41(0.5 ; 2.8 \mathrm{~V} \quad 0.8 \mathrm{~V})$ & \\
\hline $\mathrm{i}$ & $\mathrm{LP} 30+\mathrm{VC}$ & 0.7 & RT $(0.5 ; 2.8 \mathrm{~V} \quad 0.25 \mathrm{~V})$ & $41(0.5 ; 2.8 \mathrm{~V} \quad 0.8 \mathrm{~V})$ & \\
\hline
\end{tabular}




\subsection{Targeted electrochemical cycling for post mortem investigations}

To investigate the several reaction steps occurring in the dis charging process, two electrodes (Table 1, cells (h) and (i)) were synthesized, assembled with VC containing electrolyte and dis charged to different specific potentials. The first cell was discharged from 2.8 to $0.8 \mathrm{~V}$, just after the potential where the reduction of $\mathrm{Sn}^{\mathrm{II}} \mathrm{O}$ and the electrolyte is expected, the second one from 2.8 down to $0.25 \mathrm{~V}$, the potential after the expected alloying with lithium.

For the post mortem characterization of the electrode material the cycled half cells were disassembled and rinsed in the glove box using DMC. To avoid atmospheric contact after disassembling, the electrodes were transported in gas tight transfer boxes. In case of XRD a special gas tight sample holder was used, in case of XPS a glove box attached to the instrument was available.

Phase composition of the deposited and dried layers, as well as the cycled layers was evaluated using $\mathrm{X}$ ray diffraction (D8 Advanced, Bruker Corporation, Billerica, USA). To investigate layer morphologies and elemental composition, a field emission scan ning electron microscope (FE SEM, Zeiss Supra 55, Zeiss, Oberko chen, Germany) equipped with an energy dispersive $\mathrm{X}$ ray spectrometer (EDS, EDAX, AMETEK, Mahwah, USA) was used. The acceleration voltage was set to $2 \mathrm{kV}$ for imaging and $15 \mathrm{kV}$ were used for EDS elemental mapping. The samples were investigated without any sputter coating. The chemical composition of topmost electrode surfaces was analyzed using $X$ ray photoelectron spec troscopy (XPS, K Alpha spectrometer, ThermoFisher Scientific, East Grinstead, UK). Data acquisition and processing using the Thermo Avantage software is described elsewhere [19]. All samples were

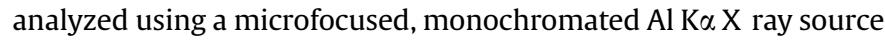
(400 $\mu \mathrm{m}$ spot size). The K Alpha charge compensation system was employed during analysis, using electrons of $8 \mathrm{eV}$ energy and low energy argon ions to prevent any localized charge build up. The spectra were fitted with one or more Voigt profiles (binding energy uncertainty: $\pm 0.2 \mathrm{eV}$ ). All spectra were referenced to the $\mathrm{C} 1 \mathrm{~s}$ peak of hydrocarbon at $285.0 \mathrm{eV}$ binding energy, controlled by means of the well known photoelectron peaks of metallic $\mathrm{Cu}, \mathrm{Ag}$, and $\mathrm{Au}$.

\section{Results and discussion}

Long term cycling data of two cells (Table 1, cells (a) and (b)) with different electrolyte compositions are depicted in Fig. 1. The

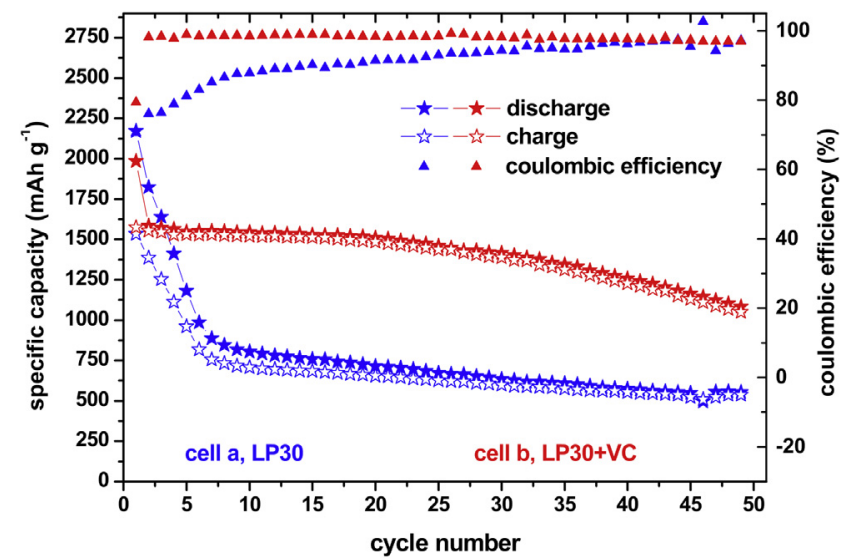

Fig. 1. Comparison of the electrochemical performance of cell (a) with pure LP30 electrolyte and cell (b) with LP30 + VC. For details concerning cells see Table 1. Voltage profiles of the 1st, 3rd, 5th, 10th and 30th cycle of both cells are shown in the Supplementary section (Fig. S1). starting capacities of both cells are relative comparable to each other. While the cell with LP30 electrolyte shows a pronounced decrease of the specific capacity and large capacity differences between discharge and charge (poor coulombic efficiency) espe cially for the first 10 cycles, the capacity of the cell with the addition of VC seems to be more constant with coeval better coulombic ef ficiency. The degradation of this composite material in combination with LP30 was discussed in detail in our previous work [20]. In addition, voltage profiles are shown in Figs. S1 and S2 (Supporting information).

We assume the high capacity values can be attributed to the properties of the composite material consisting of Sn and hydro carbons. As already mentioned, hydrocarbons exhibit high specific capacities, which depend on the $\mathrm{H} / \mathrm{C}$ ratio [4-11]. Using the measured $\mathrm{H} / \mathrm{C}$ ratio of 1.6 , a capacity resulting from the hydrocar bon material of around $2450 \mathrm{mAh} \mathrm{g}^{-1}$ can be estimated, when extrapolating data from Zheng et al. [4,5] and Dahn et al. [11] (see Supporting information, Fig. S3). High capacities of the hydrocar bons in the same order of magnitude were already published by Chen et al. [9] and Fey et al. [10], and therefore seem to be realistic. Together with the values of Sn (994 $\mathrm{mAh} \mathrm{g}^{-1}$ ) a relative high spe cific capacity of the composite material can be expected.

Looking at Fig. 1, it can be seen that the tin/hydrocarbon com posite in combination with the LP30 + VC electrolyte shows improved electrochemical performance. This finding is supported by the reports of several research groups [21-25], which also show better electrochemical performance of lithium ion batteries when using the additive VC in the electrolyte. These improvements are generally attributed to the advanced properties of the formed SEI [21-25]. This related SEI in VC containing electrolytes seems to be more effective in preventing the electrolyte from an ongoing degradation and therefore does not grow with cycling. Additionally, the impedance of cells is found to be almost invariant at RT upon cycling and the coulombic efficiency and irreversible capacity loss are improved. Auerbach et al. [21] attribute the enhancing influ ence of VC on the electrochemical performance to the ability of VC to form polymeric surface species during the course of its reduc tion. Surface films containing polymers are expected to be more cohesive and flexible, and thus provide better passivation proper ties compared to surface films formed in standard electrolytes without any additives.

The SEI formation of cells containing VC in the electrolyte is investigated in more detail using XPS. The C $1 \mathrm{~s}, \mathrm{O} 1 \mathrm{~s}$, and Li $1 \mathrm{~s}$ spectra of the pristine electrode and of the electrodes of two cells cycled down to $0.8 \mathrm{~V}$ and $0.25 \mathrm{~V}$ (Table 1, cells (h) and (i)), respectively, are shown in Fig. 2.

As already mentioned, and also described by Auerbach et al. [21] and El Ouatani et al. [26], the improved electrochemical perfor mance of VC containing cells can be explained by the ability of VC to form polymeric surface species during the course of its reduction. The components at an exceptionally high binding energy of $\mathrm{O}$ 1s $\quad 534.5 \mathrm{eV}$ and C $1 \mathrm{~s} \quad 291.0 \mathrm{eV}$ seems likely to originate from a VC polymer. According to El Ouatani et al. [26] only the double bond of $\mathrm{VC}$ is polymerized and a ring opening polymerization of the VC does not take place. The VC polymer obviously is formed during cycling, and its amount is doubled up during the cycling from 0.8 to $0.25 \mathrm{~V}$. However, the exact structure and composition of this polymer still remains an open question. XPS measurements proof, that this polymeric surface species are not formed in a cell without VC. Comparison of the $\mathrm{C} 1 \mathrm{~s}$ and $\mathrm{O} 1 \mathrm{~s}$ spectra of electrodes cycled with and without VC in the electrolyte is shown in the Supporting information (Fig. S4).

Beside the VC based polymer, XPS proves that the formed SEI also includes further decomposition products of the electrolyte. After discharging from 2.8 to $0.25 \mathrm{~V}$ the XPS analysis of the 


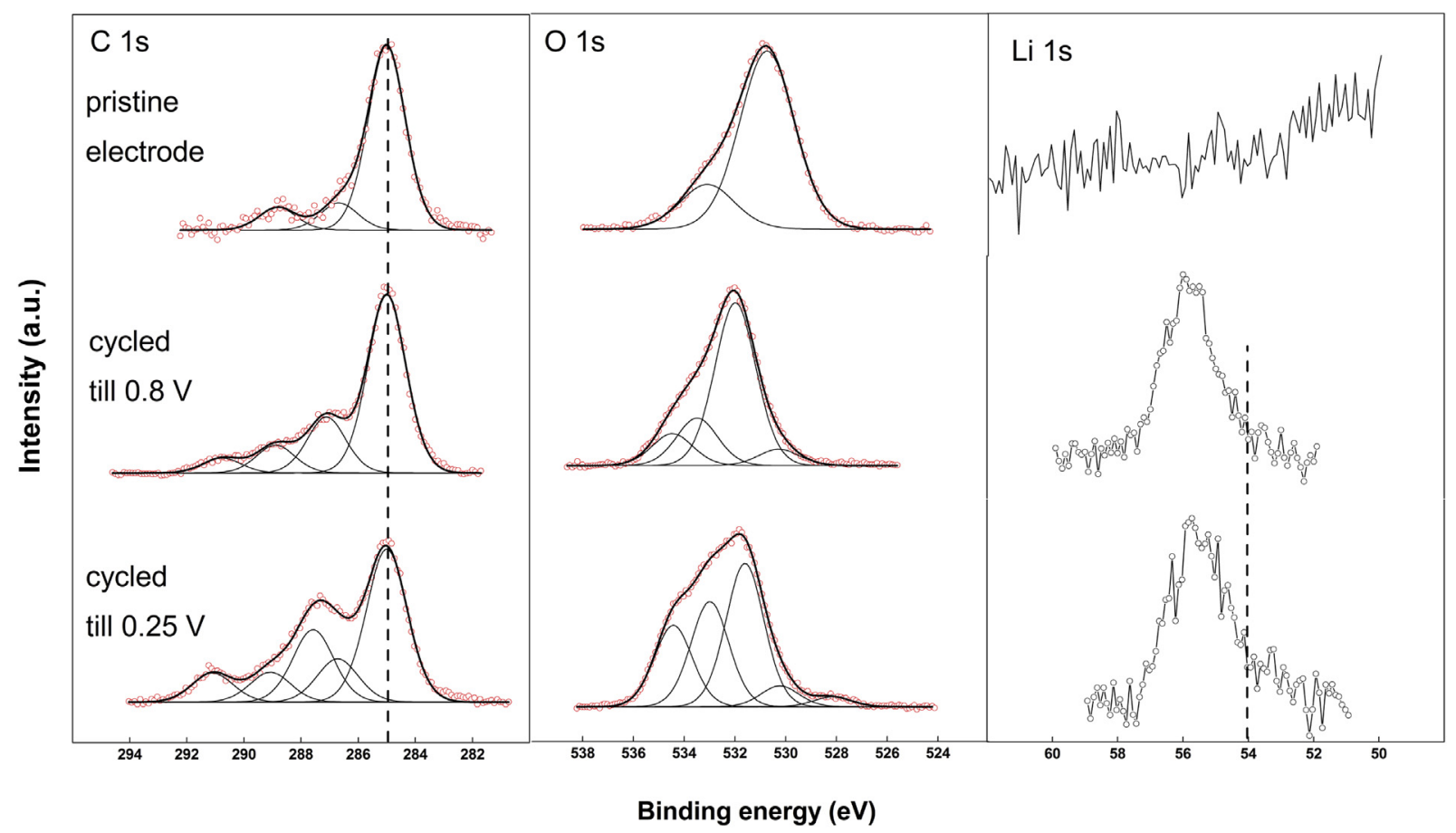

Fig. 2. C 1s, 0 1s, and Li 1s XP spectra of a pristine electrode and electrodes cycled to $0.8 \mathrm{~V}$ (Table 1 , cell (h)) and $0.25 \mathrm{~V}$ (Table 1 , cell (i)), respectively.

electrode surface shows increasing peak intensities at $286.6 \mathrm{eV}$, $287.6 \mathrm{eV}$ and $289.0 \mathrm{eV}$. These peaks appear in addition to the main $\mathrm{C}$ $1 \mathrm{~s}$ component at $285.0 \mathrm{eV}$ of hydrocarbons on pristine electrode surfaces. In a good agreement with literature [27] these compo nents can be attributed to alkoxy , ethereal , carbonyl , and alkyl carbonate species. The corresponding $\mathrm{O}$ 1s peaks, cf. Fig. 2 at $531.6 \mathrm{eV}, 532.1 \mathrm{eV}$ and $533.0 \mathrm{eV}$ corroborate these findings [28]. These compounds result from the direct decomposition of the carbonates of the electrolyte (EC, DMC). The additional decompo sition of the conducting salt $\left(\mathrm{LiPF}_{6}\right)$ is proven by the appearance of peaks ascribed to lithium fluoride ( $\mathrm{F} 1 \mathrm{~s}$ at $685.1 \mathrm{eV}$ ) and several fluorinated lithium phosphate species (F 1s at $687.3 \mathrm{eV}, \mathrm{P} 2 \mathrm{p}$ at 134-137 eV) [28]. The Li 1s spectra of both cycled electrodes in Fig. 2 show a rather broad main peak, containing various lithium species. Due to the low sensitivity for lithium and only slight binding energy shifts between different lithium species this peak was not further deconvolved. Nevertheless, the Li 1s spectra of both cycled electrodes show a tailing at lower binding energies. This indicates the presence of $\mathrm{Li}_{2} \mathrm{O}$ and is also confirmed by the corre sponding O 1 s component at $528.2 \mathrm{eV}$ [29].

To prove the significant difference of the SEI formation in a cell with pure LP30 electrolyte (Table 1, cell (c)) and VC containing electrolyte (Table 1, cell (d)), EIS results are compared after the first, second and third discharge cycle (Fig. 3). The semicircle at high frequencies within the Nyquist plot is representing the resistance of the SEI [27]. The aim of this measurement is to evaluate SEI related resistance of the 2 nd and 3rd cycle compared to the 1 st one. For the VC free electrolyte (Fig. 3a) the semicircle is increasing with increasing cycling. The increasing resistance is due to the increasing SEI thickness with cycling. In contrast, a pronounced influence of VC in the electrolyte can be seen in Fig. 3b. The SEI formation occurs only in the first discharging cycle, as no increase of the SEI related semicircle for the following cycles is visible. This behavior is in a good agreement with results from Chen et al. [22].

Within the discharging process of the half cell, the Sn based composite electrode material undergoes specific reactions with both, the electrolyte, and the lithium of the counter electrode occurring at related potentials. To evaluate the involved reactions in more detail, the first, second, and third discharging processes of the cell with VC containing electrolyte (from Fig. 1) are depicted as a differential capacity plot in Fig. 4 (specific capacity $C_{\mathrm{sp}}$ Vs. potential $U)$. In this diagram every peak is representing a chemical reaction. Starting at $2 \mathrm{~V}$, the first region of reactions represents the reduction of tin monoxide [30] and electrolyte [31,32] (formation of SEI) ac cording to the reactions

$\mathrm{Sn}^{\mathrm{II}} \mathrm{O}+2 \mathrm{Li}^{+}+2 \mathrm{e}^{-} \rightarrow \mathrm{Sn}^{0}+\mathrm{Li}_{2} \mathrm{O}$

and

Electrolyte $+x \mathrm{Li}^{+}+x \mathrm{e}^{-} \rightarrow$ SEI

Reaction (2) is typically assumed to be irreversible, and is ex pected in the first discharging process only. In accordance, the respective peak in Fig. 4 is only visible in the first cycle. After this cycle the coulombic efficiency is nearly constant and close to $99 \%$ (see also Fig. 1, VC containing electrolyte). All subsequent reactions in the differential capacity plot are representing the alloying of tin and lithium, following the general reaction

$\mathrm{Sn}+x \mathrm{Li}^{+}+x \mathrm{e}^{-} \rightarrow \mathrm{Li}_{x} \mathrm{Sn}$

Several alloy reactions can be seen in Fig. 4 and are summarized in Table 2 together with the observed potential values. The assignment is based on literature $[12,30,33,34]$. It can be seen that the lithium richest alloy, $\mathrm{Li}_{22} \mathrm{Sn}_{5}$, was formed.

Following the discharging process, it is assumed, that the reac tion after the lithium-tin alloying is attributed to the formation of chemical bonds between hydrocarbons and lithium $\left(\mathrm{Li}_{x} \mathrm{H}_{n} \mathrm{C}_{m}\right)$. This reaction was described in literature $[4,5,8]$ to occur near $0 \mathrm{~V}$ vs. $\mathrm{Li} / \mathrm{Li}^{+}$. While Mabuchi et al. [8] propose that the capacity arise from the insertion of lithium within nanoscopic cavities of the material, 
(a)

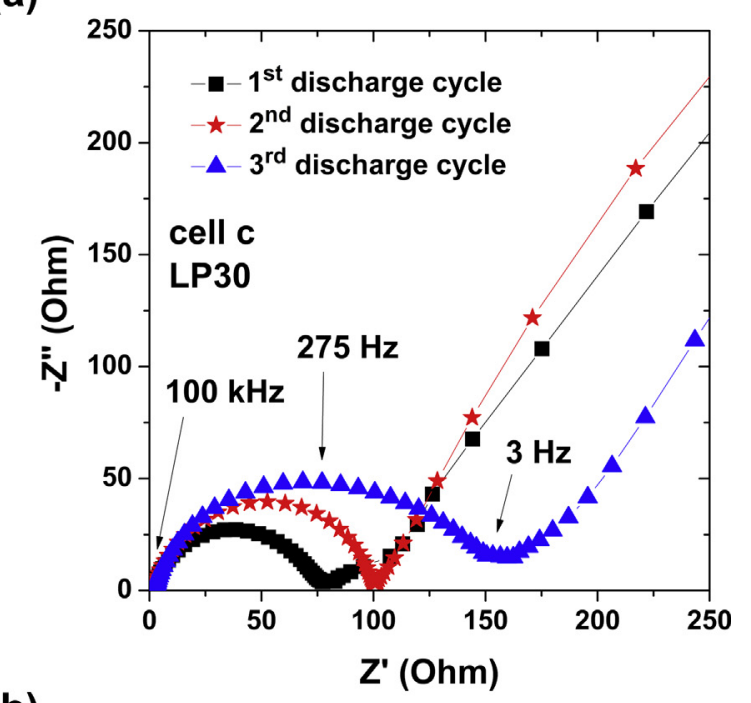

(b)

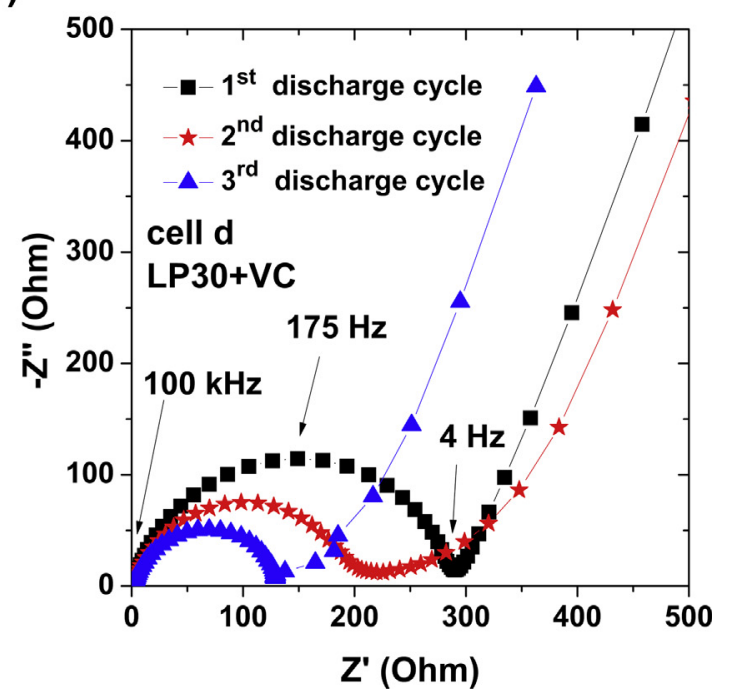

Fig. 3. Nyquist plots after the first, second, and third discharge cycle with a) pure LP30 electrolyte and b) VC containing LP30 electrolyte. While the SEI in the pure electrolyte is constantly growing with cycling, in the VC containing electrolyte the SEI formation is completed already after the first cycle.

Zheng et al. $[4,5]$ describe, that the lithium atoms may bind on hydrogen terminated edges of hexagonal carbon fragments, with local geometries, analogous to the organolithium molecule $\mathrm{C}_{2} \mathrm{H}_{2} \mathrm{Li}_{2}$.

To evaluate the involved phases during cycling, $\mathrm{X}$ ray diffraction data of electrodes cycled to three selected potential steps are shown in Fig. 5. The first pattern shows the non cycled nanoparticle film deposited on $\mathrm{Ni}$ substrates, the second pattern shows an electrode cycled from 2.8 down to $0.8 \mathrm{~V}$ (Table 1 , cell $(\mathrm{h})$ ), and finally, the third pattern shows an electrode cycled down to $0.25 \mathrm{~V}$ (Table 1, cell (i)). The figure also includes the positions and related intensities for the most expected phases.

For the non cycled material the occurrence of tetragonal $\mathrm{Sn}(\mathrm{t}$ $\mathrm{Sn}$ ) and tetragonal $\mathrm{SnO}$ is found. Following the discharging process down to $0.8 \mathrm{~V}$ the pattern is changing, according to Reaction (1). However, only tetragonal $\mathrm{Sn}$ is observed, whereas $\mathrm{Li}_{2} \mathrm{O}$ could not be detected, although the XPS investigation indicates the presences of $\mathrm{Li}_{2} \mathrm{O}$. One reason might be that the $\mathrm{Li}_{2} \mathrm{O}$ is amorphous or poorly crystallized. Additionally, if $\mathrm{Li}_{2} \mathrm{O}$ is formed as a thin layer around the

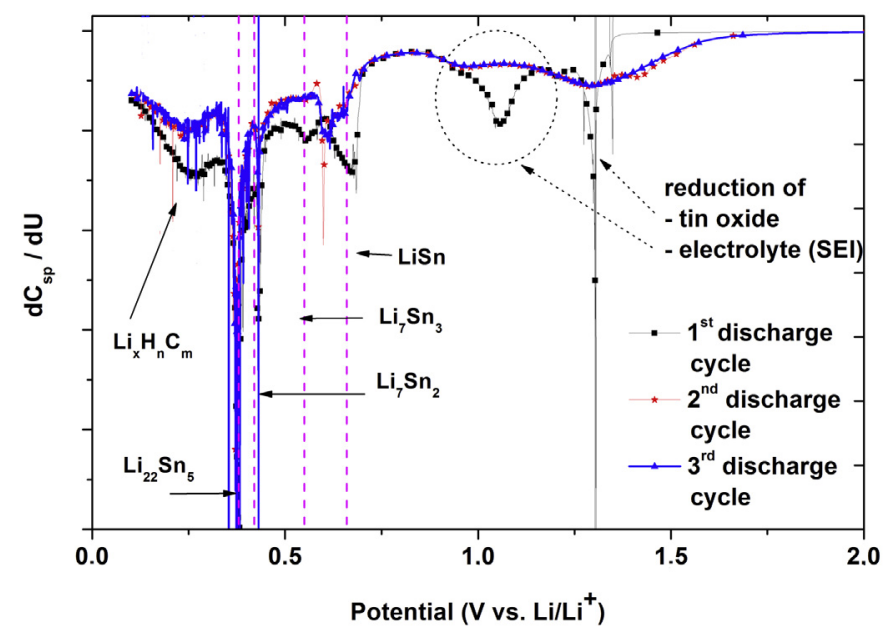

Fig. 4. Differential specific capacity plots for the first, second, and third discharging processes of a cell with VC containing electrolyte (Table 1, cell (b)). Each peak represents a chemical reaction.

Sn nanoparticles it will not be detectable using XRD. Further dis charging down to $0.25 \mathrm{~V}$ causes again changes of the pattern. The electrode at this potential obviously is a mixture of tetragonal $\mathrm{Sn}$ and LiSn, representing the first alloying reaction of $\mathrm{Li}$ and $\mathrm{Sn}$. While the differential capacity plot of the discharging process of this cell shows that the lithium richest phase $\left(\mathrm{Li}_{22} \mathrm{Sn}_{5}\right)$ finally is formed (like in Fig. 4), this phase cannot be observed in the XRD measurements. It cannot be excluded that this phase is formed as nano crystalline material with sizes below the detection limit of XRD. Considering that XRD measurements are performed after destroying the test cells, modifications of the whole system occurring during the dis assembling of the cells cannot be excluded. Nevertheless, XRD patterns are showing phase changes during the discharging process and the formation of $\mathrm{Li}-\mathrm{Sn}$ alloys.

\subsection{Influence of the current density on the specific capacity}

Although the cycling properties of cells assembled with elec trolytes containing the additive VC are promising at a constant and low current density, the influence of the current density on the specific capacity in this electrode system is obvious (Fig. 6). Selected voltage profiles are shown in the Supporting information, Fig. S5. While the current density is increased gradually, gradual decreases in the specific capacity are observed. Moreover, with increasing current density, the inclination of degradation becomes steeper, too. This behavior is found to be most pronounced at a current density of $821 \mathrm{~mA} \mathrm{~g}^{-1}$. After 10 cycles with this current density, the material seems to be damaged strongly. Even after switching back to a current density of $41 \mathrm{~mA} \mathrm{~g}^{-1}$ (the current density which actually resulted in predominantly relative constant capacities) degradation and fading of capacities continued, without

Table 2

Observed potentials vs. $\mathrm{Li} / \mathrm{Li}^{+}$and corresponding reactions to tin and lithium alloys.

\begin{tabular}{ll}
\hline Potential vs. $\mathrm{Li} / \mathrm{Li}^{+}(\mathrm{V})$ & Alloy \\
\hline 0.66 & $\mathrm{LiSn}$ \\
0.55 & $\mathrm{Li}_{7} \mathrm{Sn}_{3}$ \\
0.42 & $\mathrm{Li}_{7} \mathrm{Sn}_{2}$ \\
0.38 & $\mathrm{Li}_{22} \mathrm{Sn}_{5}$ \\
\hline
\end{tabular}




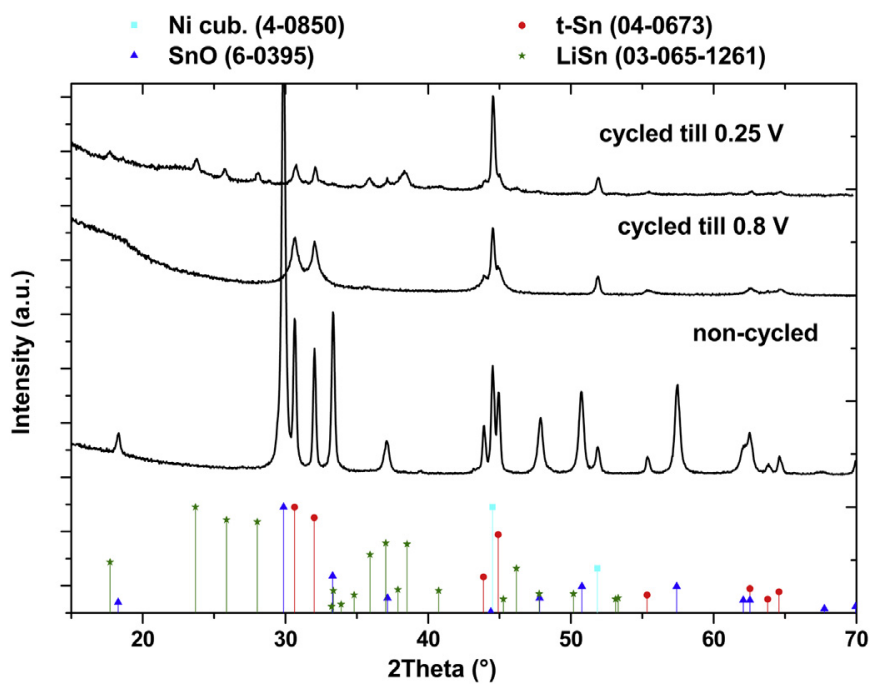

Fig. 5. X-ray diffraction patterns of a non-cycled electrode, an electrode cycled from 2.8 down to $0.8 \mathrm{~V}$, and finally an electrode cycled down to $0.25 \mathrm{~V}$. All patterns are compared to JCPDS powder database.

losing good coulombic efficiency. The reason seems to be a destruction of the electrode, as shown by SEM (Fig. 7). The non cycled electrode shows a homogeneous and crack free morphology. This can be observed over the whole area and is shown in Fig. 7a. After finishing the cycling measurement, a bulged layer covered with cracks, can be clearly seen in Fig. 7b and c. Cracks can lead to detachment of the material, accompanied by the loss of electronic contact between active particles as well as between active material and the current collector. Therefore, the amount of material which is accessible for lithium storage decreases [12]. It is assumed, that this destruction occur at a current density greater than 164 but less than $821 \mathrm{~mA} \mathrm{~g}^{-1}$ and is responsible for the following degradation of the specific capacities.

\subsection{Influence of temperature on specific capacity}

The electrochemical performance of cells using VC is dependent on the environmental temperature as well. Fig. 8 illustrates this

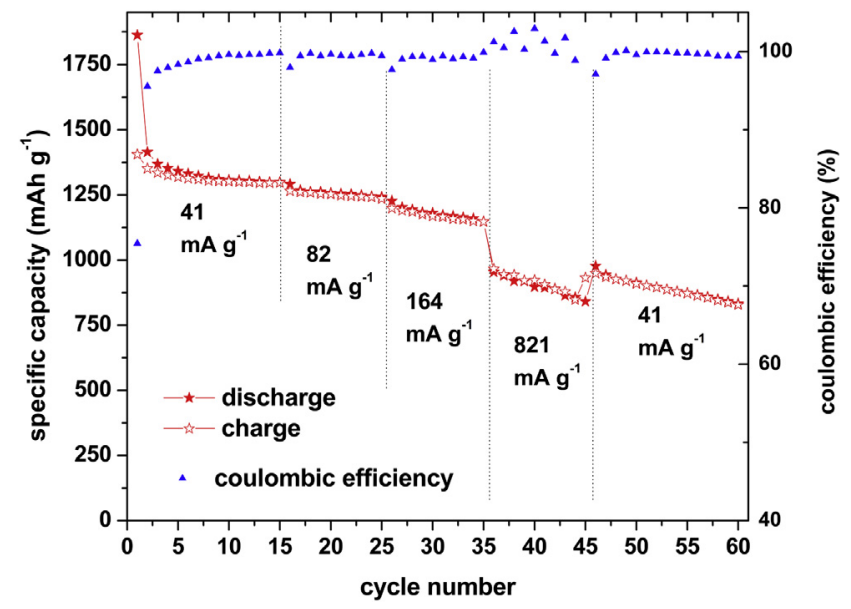

Fig. 6. Influence of current density on specific capacity of a cell containing VC in the electrolyte (Table 1, cell (e)). With increasing current density, the specific capacity decreases accompanied by increasing degradation. Voltage profiles of the $1 \mathrm{st}, 5 \mathrm{th}, 10 \mathrm{th}$ 20th, 30th, 36th, 38th, 40th and 50th cycle are shown in the Supplementary section (Fig. S5). behavior. Selected voltage profiles are shown in the Supporting information, Fig. S6. For the first treatment at RT, a relative con stant capacity behavior can be observed in agreement with Fig. 1 (LP30 + VC). Increasing the temperature from RT to $40{ }^{\circ} \mathrm{C}$ causes a discrete capacity increase, but with ongoing cycling the degra dation is becoming steeper. The initial increase of specific capacity can be explained with a combination of reasons. The electrical and the ionic conductivity of the electrolyte increase, respectively $[35,36]$. At higher temperatures the viscosity of the electrolyte decreases, so with increasing mobility of the ions the capacities increase. Furthermore, the gradient of overpotentials (ohmic and diffusion) is changing drastically when changing the environmental temperature. The overpotential (drop of potential) decreases with increasing environmental temperature. Consequently, the potential of the cell increases, resulting in a specific capacity increase. An explanation of this initial increase of specific capacity due to tem perature increase can be found in more detail in our previous work [37].

With higher capacities at $40{ }^{\circ} \mathrm{C}$ (11th cycle ca. $1435 \mathrm{mAh} \mathrm{g}{ }^{-1}$ compared to ca. $1587 \mathrm{mAh} \mathrm{g}^{-1}$ in the 13th cycle) it can be assumed, that more $\mathrm{Li}^{+}$ions are introduced in the electrode. It is known, that the introduction of $\mathrm{Li}^{+}$ions causes huge volume changes in the $\mathrm{Sn}$ material [38]. Consequently, the higher amount of $\mathrm{Li}^{+}$ions, resulting from increased $\mathrm{Li}^{+}$mobility with temperature, increases the volume change compared to RT, resulting in huger loss of active material and hence decreased capacity for the following cycles.

Additionally, at $40{ }^{\circ} \mathrm{C}$ enhanced electrolyte reduction (SEI for mation) takes place [39]. This phenomenon is visible in Fig. 9a, showing the differential capacity diagram of the 11 th cycle (RT), the 13th cycle $\left(40{ }^{\circ} \mathrm{C}\right)$, and the 23 rd cycle (again RT). The potential range was set from 2 to $0.75 \mathrm{~V}$, the region where the SEI formation is expected. After switching the temperature to $40^{\circ} \mathrm{C}$, an additional peak in the region between 1.5 and $1 \mathrm{~V}$ appears. This region is believed to be connected to the reduction of electrolyte (SEI for mation). With switching the environmental temperature back to $\mathrm{RT}$, the peak according to SEI formation in Fig. 9a (23rd cycle) dis appears. Coevally, the coulombic efficiency rises to the same value as for the previous treatment at RT. According to this, the SEI is not continuously formed at RT and consequently the capacities should not degrade much. But, with ongoing cycling the specific capacities degrade even at RT. The pretreatment at $40{ }^{\circ} \mathrm{C}$ seems to have already destroyed the electrode to a certain extent. Switching to $5{ }^{\circ} \mathrm{C}$, the capacities are becoming smaller and the same degradation as before can be observed. The initial decrease of the specific ca pacity can be attributed to the decrease of the electrical and the ionic conductivity and also to the increase of the overpotentials at $5{ }^{\circ} \mathrm{C}$. Surprisingly, at $5{ }^{\circ} \mathrm{C}$ a strong decrease of coulombic efficiency in combination with very fluctuating values can be observed. Fig. $9 \mathrm{~b}$ shows a differential capacity plot of the 33rd cycle (RT) and the 34 th cycle $\left(5^{\circ} \mathrm{C}\right)$. It can be seen that the poor coulombic efficiency at $5{ }^{\circ} \mathrm{C}$ cannot be attributed to the SEI formation, as no additional peak of the reduction of electrolyte appears at $40^{\circ} \mathrm{C}$, as shown e.g. in Fig. 9a.

The influence of temperature on the electrochemical perfor mance of this material in combination with the electrolyte LP30 was reported in previous work [37]. Looking at $0{ }^{\circ} \mathrm{C}$ the coulombic efficiency is nearly at $100 \%$. The observed poor coulombic efficiency in combination with fluctuating values at $5{ }^{\circ} \mathrm{C}$ in Fig. 8 must be attributed to VC. Comparable investigations without VC presented in Ref. [37] show a coulombic efficiency around $100 \%$. One reason might be that the melting point of $\mathrm{VC}$ is close to $19{ }^{\circ} \mathrm{C}$ (given compound specification), and so the viscosity of the electrolyte might change at $5{ }^{\circ} \mathrm{C}$. The switching again to RT causes a little discrete capacity increase but the fading trend could not be detained. 

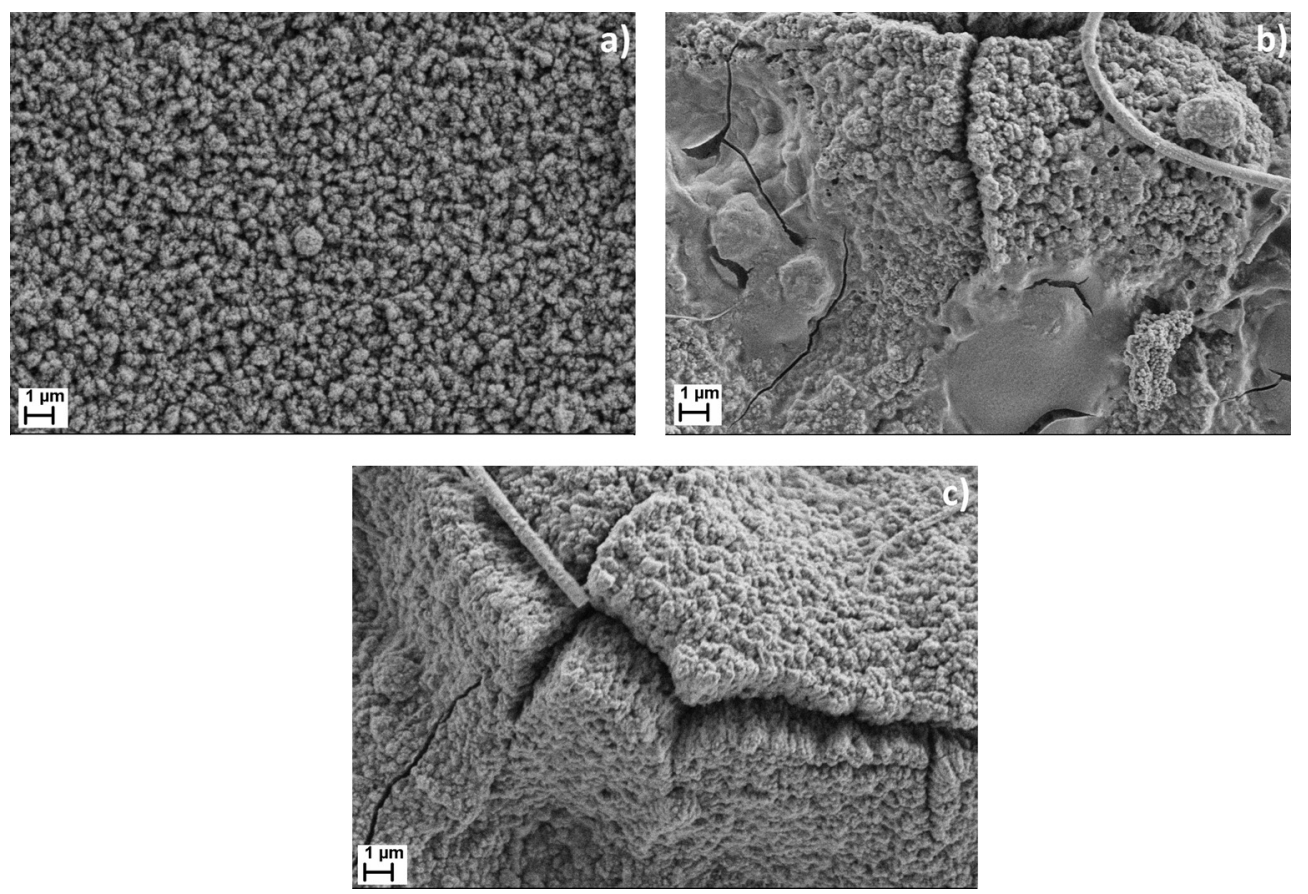

Fig. 7. SEM characterization of electrode surfaces before (a) and after finishing the cyclic measurement (b, c). Large destruction of the bulged electrode layer covered with cracks can clearly be seen. It is assumed, that this destruction is responsible for the degradation of the specific capacities.

To confirm the enhanced electrolyte reduction (SEI formation) at elevated temperatures, EIS was performed with a new cell after cycling (Table 1, cell g). The resulting semicircles in the Nyquist plot (Fig. 10) are representing the resistance of the SEI. It can be seen, that the semicircles for both cycles at RT (discharging cycle 2 and 3 ) are smaller than for the cycle at $40{ }^{\circ} \mathrm{C}$ (discharging cycle 4 ). Hence, the resistance of SEI at $40{ }^{\circ} \mathrm{C}$ is larger compared to that at RT, representing enhanced electrolyte reduction (SEI formation) at elevated temperatures. With continuous cycling at elevated tem perature the repetitive formed SEI may penetrate into pores of the electrode and in addition may also penetrate into pores of the separator. This may result in a decrease of accessible surface area due to this continuous SEI formation [39].

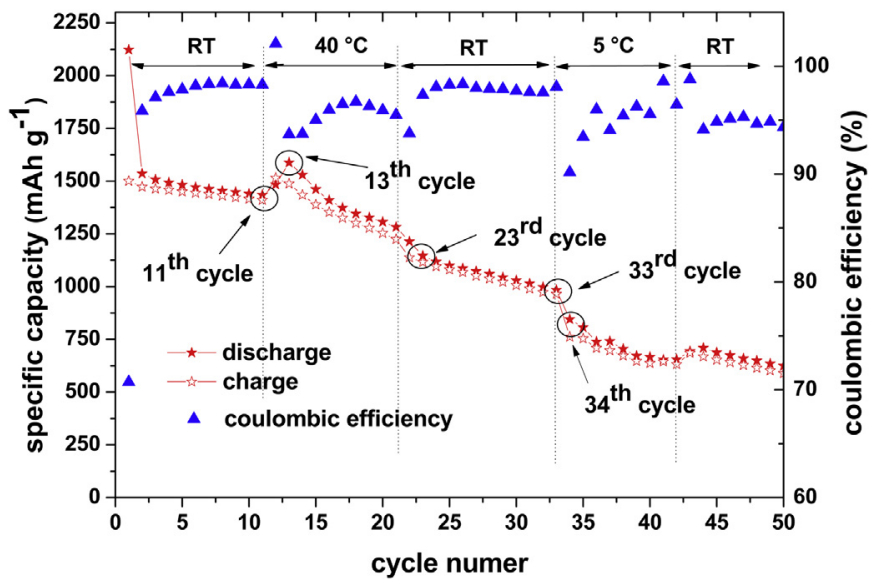

Fig. 8. Long term cycling measurement under different thermal conditions of a cell containing VC in the electrolyte. Voltage profiles of the 1st, 5th, 13th, 30th and 37th cycle are shown in the Supplementary section (Fig. S6).
In summary, at elevated temperature huger volume changes and also enhanced SEI formation takes place. With diminishing the amount of active material and also the accessibility of the electrode in combination with increasing impedance, less $\mathrm{Li}^{+}$ions can be stored, resulting in a degradation of specific capacity for the following cycles.

To have an optical proof of the SEI, a cell was characterized by SEM after finishing the cycling experiments (Table 1, cell (f)). Fig. 11 shows the cross section SEM image of this electrode. In the regions near the surface, a layer exhibiting different morphology in com parison to the rest of the film is clearly visible. This thin film is assumed to be the SEI layer.

EDS elemental mapping (Fig. 12) shows the elemental compo sition of two different electrodes. A non cycled electrode is compared with the electrode after finishing the temperature cycling measurement (Table 1, cell $\mathrm{f}$ ). The cross section view of the non cycled electrode is obtained by scratching the layer with a blade after synthesis. The cross section view of the cycled electrode was possible without further manipulation, because some regions of the film cracked and some pieces were split out. The elemental maps are superimposed images of the analyzed elements $\mathrm{Sn}, \mathrm{Ni}, \mathrm{O}$ and $C$, respectively. In the pristine composite electrode the ele ments Sn, C, and $\mathrm{O}$ are homogenously distributed. Additionally, Ni, stemming from the current collector, is found in regions without any electrode material.

For the cycled electrode the result is somehow different. The element $\mathrm{Sn}$ is predominantly found only in the cross section of the film. Inside the cracks, which are distributed on the surface, only Sn and $\mathrm{Ni}$ are detectable, whereas the surface of the film is predomi nantly consisting of $C$ and $O$. This can be taken as a proof of a cover layer on top of $\mathrm{Sn}$ and $\mathrm{Ni}$, where $\mathrm{Sn}$ is representing the electrode material and $\mathrm{Ni}$ the current collector. In accordance to the XPS measurements, the assumption of a $\mathrm{C}$ and $\mathrm{O}$ containing SEI layer on the surface of the electrode is confirmed by SEM investigations and EDS elemental mapping. 
(a)

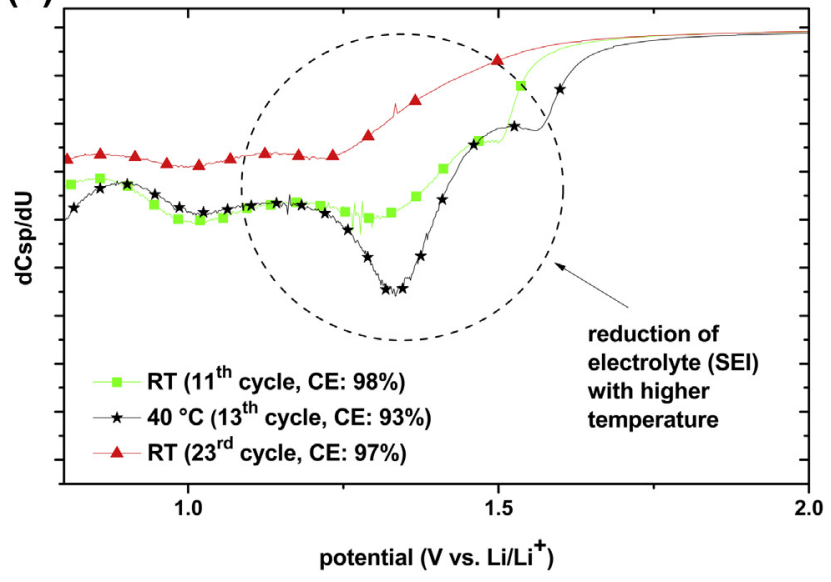

(b)

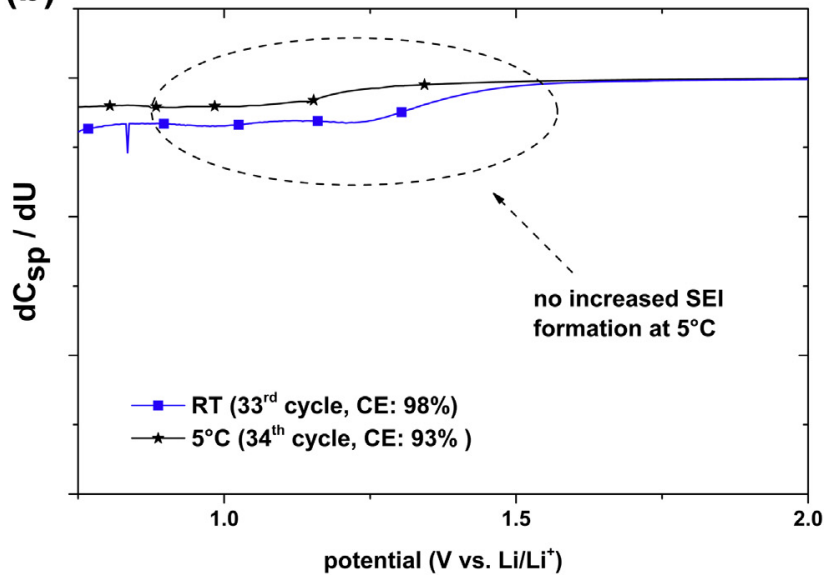

Fig. 9. Differential capacity plots (a) extracted from cycling data of the 11th, 13th and 23rd cycles and (b) extracted from the 33rd and 34th cycles, respectively. The potential range was set between 2 and $0.75 \mathrm{~V}$, corresponding to the region of expected SEI formation.

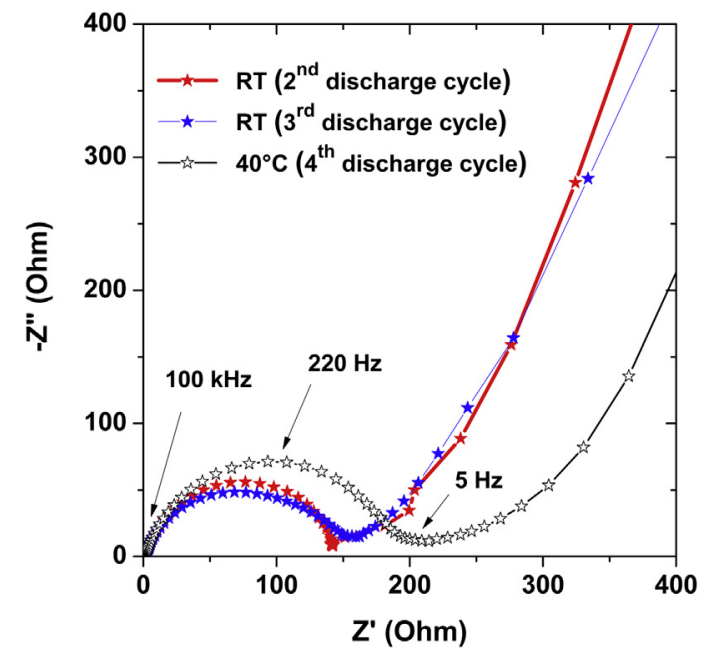

Fig. 10. Nyquist plot of EIS measurements at RT (2nd and 3rd cycle) and at $40{ }^{\circ} \mathrm{C}$ (4th cycle) of a cell containing VC in the electrolyte. At higher temperature the semi-circle in the Nyquist plot is becoming large, meaning the resistance of the SEI increases. This is a direct proof of enhanced electrolyte reduction and SEI formation.

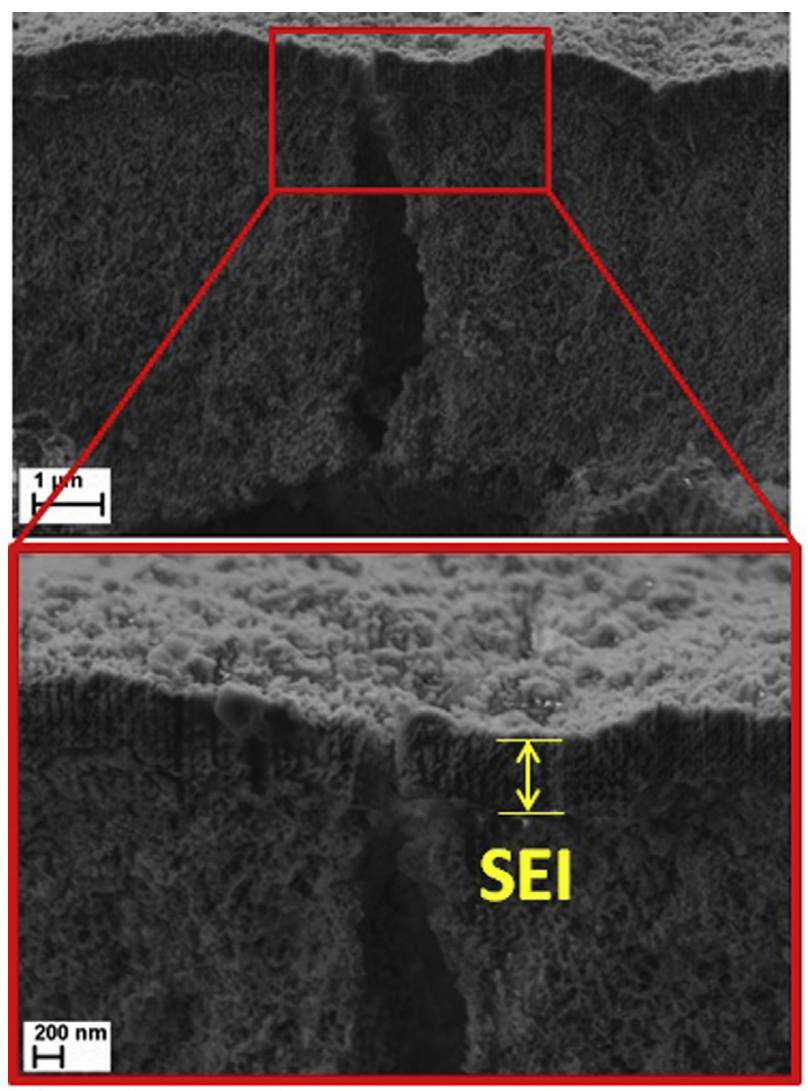

Fig. 11. Cross sectional SEM image of the temperature-cycled Sn composite electrode after cycling (Table 1 , cell (f)).

\section{Summary and conclusion}

In this work a comprehensive electrochemical characterization of tin based and hydrocarbon containing nano composite elec trodes for Li ion cells was presented. The high specific capacities of this material can be attributed to the presence of hydrocarbons with an $\mathrm{H} / \mathrm{C}$ ratio around 1.6. It was shown, that the additive $\mathrm{VC}$ in the electrolyte improves the cycling performance, due to improved SEI formation. XPS measurements led to the conclusion, that a VC based polymer is produced during cycling. Moreover, XPS in vestigations proved that the formed SEI additionally consists of compounds originating from the decomposition of the electrolyte, and the conducting salt as well. Variation of temperature during the cycling demonstrated, that enhanced temperature enlarges the specific capacity, but also the degradation. Additionally, when increasing the current density, the capacity decreases. The best electrochemical performance could be obtained using VC in the electrolyte, and cycling at RT with a current density below $164 \mathrm{~mA} \mathrm{~g}^{-1}$. In agreement with XPS measurements, EDS mea surements showed that the SEI layer contains $C$ and O. XRD revealed the non cycled electrode to be a mixture of tetragonal $\mathrm{Sn}$ and SnO. By crossing the potential of $0.8 \mathrm{~V}$ only metallic Sn ac cording to the reduction of $\mathrm{SnO}$ and by crossing the potential of $0.25 \mathrm{~V}$ a mixture of metallic Sn and LiSn according to the lithiumtin alloying reaction could be detected.

In conclusion, a good electrochemical performance of the tin based hydrocarbon electrode material can be expected using a VC containing electrolyte, current densities below $164 \mathrm{~mA} \mathrm{~g}^{-1}$, and RT as operating temperature. 


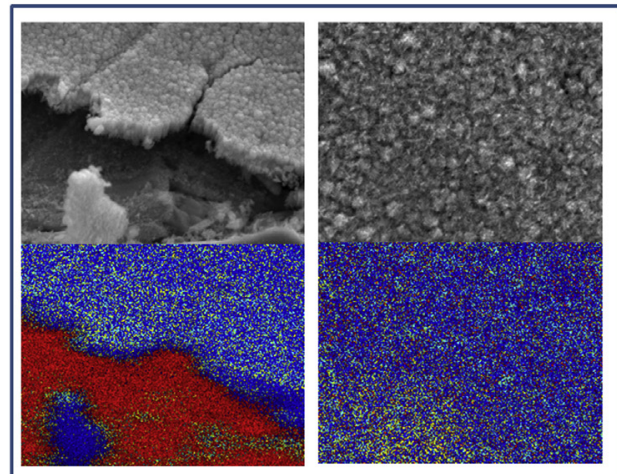

a) non cycled

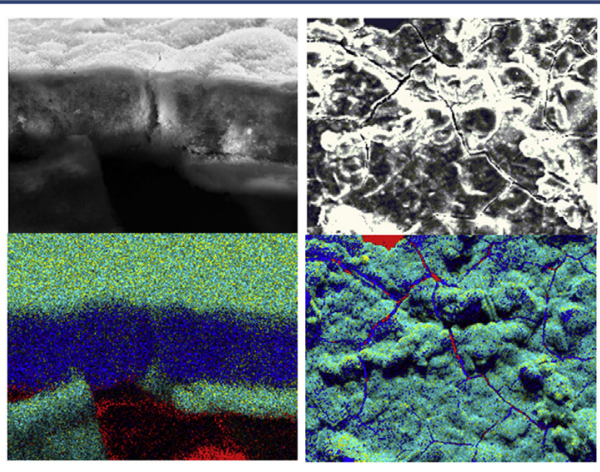

b) cycled

Fig. 12. EDS elemental mapping of a cross section and top view of (a) a non-cycled electrode and (b) of a cycled electrode (Table 1, cell (f)).

\section{Acknowledgments}

The authors acknowledge support from B. Bergfeldt (Karlsruhe Institute of Technology, Institute for Technical Chemistry) for $\mathrm{H} / \mathrm{C}$ analysis and C. Odemer (Karlsruhe Institute of Technology, Institute for Applied Materials) for TGA-DSC analysis.

\section{References}

[1] Y. Idota, T. Kubota, A. Matsufuji, Y. Maekawa, T. Miyasaka, Science 276 (1997) 13951397.

[2] A.R. Kamali, D.J. Fray, Rev. Adv. Mater. Sci. 27 (2011) 1424.

[3] M. Wachtler, J.O. Besenhard, M. Winter, J. Power Sources 94 (2001) 189193.

[4] T. Zheng, Y. Liu, E.W. Fuller, S. Tseng, U. von Sacken, J.R. Dahn, J. Electrochem. Soc. 142 (1995) 25812590.

[5] T. Zheng, W.R. McKinnon, J.R. Dahn, J. Electrochem. Soc. 143 (1996) 2137 2145.

[6] S. Yata, Y. Hato, H. Kinoshita, N. Ando, A. Anekawa, T. Hashimoto, M. Yamaguchi, K. Tanaka, T. Yamabe, Synth. Met. 73 (1995) 273277.

[7] K. Sato, M. Noguchi, A. Demachi, N. Oki, M. Endo, Science 264 (1994) 556558

[8] A. Mabuchi, K. Tokumitsu, H. Fujimoto, T. Kasuh, J. Electrochem. Soc. 142 (1995) 10411046

[9] W. Chen, Z. Zhu, S. Li, C. Chen, L. Yan, Nanoscale 4 (2012) 21242129.

[10] G.T.-K. Fey, D.C. Lee, Y.Y. Lin, T.P. Kumar, Synth. Met. 139 (2003) 7180.

[11] J.R. Dahn, T. Zheng, Y. Liu, J.S. Xue, Science 270 (1995) 590593.

[12] M. Winter, J.O. Besenhard, Electrochim. Acta 45 (1999) 3150.

113] Y.-C. Chen, J.-M. Chen, Y.-H. Huang, Y.-R. Lee, H.C. Shih, Surf. Coat. Technol. 202 (2007) 13131318

[14] Y. Wang, J.Y. Lee, J. Power Sources 144 (2005) 220225.

[15] C. Kim, M. Noh, M. Choi, J. Cho, B. Park, Chem. Mater. 17 (2005) 32973301.

[16] H. Li, Z. Wang, L. Chen, X. Huang, Adv. Mater. 21 (2009) 45934607.

17] D. Vollath, D.V. Szabó, J. Nanopart. Res. 8 (2006) 417428.
[18] D.V. Szabó, G. Kilibarda, S. Schlabach, V. Trouillet, M. Bruns, J. Mater. Sci. 47 (2012) 43834391

[19] K.L. Parry, A.G. Shard, R.D. Short, R.G. White, J.D. Whittle, A. Wright, Surf. Interface Anal. 38 (2006) 14971504.

[20] G. Kilibarda, D.V. Szabó, S. Schlabach, V. Winkler, M. Bruns, T. Hanemann, J. Power Sources 233 (2013) 139147.

[21] D. Aurbach, K. Gamolsky, B. Markovsky, Y. Gofer, M. Schmidt, U. Heider, Electrochim. Acta 47 (2002) 14231439.

[22] L. Chen, K. Wang, X. Xie, J. Xie, J. Power Sources 174 (2007) 538543.

[23] J.C. Burns, N.N. Sinha, D.J. Coyle, G. Jain, C.M. VanElzen, W.M. Lamanna, A. Xiao, E. Scott, J.P. Gardner, J.R. Dahn, J. Electrochem. Soc. 159 (2012) A85 A90

[24] Y. Hu, W. Kong, H. Li, X. Huang, L. Chen, Electrochem. Commun. 6 (2004) 126 131.

25] K. Abe, H. Yoshitake, T. Kitakura, T. Hattori, H. Wang, M. Yoshio, Electrochim. Acta 49 (2004) 46134622

[26] L. El Ouatani, R. Dedryvère, C. Siret, P. Biensan, S. Reynaud, P. Iratçabal, D. Gonbeau, J. Electrochem. Soc. 156 (2009) A103 A113.

[27] K. Dokko, Y. Fujita, M. Mohamedi, M. Umeda, I. Uchida, J.R. Selman, Electrochim. Acta 47 (2001) 933938.

[28] V. Etacheri, O. Haik, Y. Goffer, G.A. Roberts, I.C. Stefan, R. Fasching, D. Aurbach, Langmuir 28 (2011) 965976.

[29] K. Edström, M. Herstedt, D.P. Abraham, J. Power Sources 153 (2006) 380384.

[30] R.A. Huggins, Solid State Ionics 113115 (1998) 5767.

[31] H. Liu, D. Long, X. Liu, W. Qiao, L. Zhan, L. Ling, Electrochim. Acta 54 (2009) 57825788.

[32] M. Marcinek, L.J. Hardwick, T.J. Richardson, X. Song, R. Kostecki, J. Power Sources 173 (2007) 965971.

[33] R.A. Huggins, in: Handbook of Battery Materials, Lithium Alloy Anodes, WileyVCH Verlag GmbH, 2007, pp. 359381.

[34] J. Wang, I.D. Raistrick, R.A. Huggins, J. Electrochem. Soc. 133 (1986) 457460

[35] S.S. Zhang, K. Xu, T.R. Jow, Electrochem. Commun. 4 (2002) 928932.

[36] P.E. Stallworth, J.J. Fontanella, M.C. Wintersgill, C.D. Scheidler, J.J. Immel, S.G. Greenbaum, A.S. Gozdz J. Power Sources $81 \quad 82$ (1999) 739747.

[37] G. Kilibarda, D.V. Szabó, S. Schlabach, T. Hanemann, Int. J. Electrochem. Sci. 8 (2013) 62126219

[38] B.A. Boukamp, G.C. Lesh, R.A. Huggins, J. Electrochem. Soc. 128 (1981) 725 729.

39] J. Vetter, P. Novák, M.R. Wagner, C. Veit, K.C. Möller, J.O. Besenhard, M. Winter, M. Wohlfahrt-Mehrens, C. Vogler, A. Hammouche, J. Power Sources 147 (2005) 269281 


\section{Repository KITopen}

Dies ist ein Postprint/begutachtetes Manuskript.

\section{Empfohlene Zitierung:}

Kilibarda, G.; Schlabach, S.; Winkler, V.; Bruns, M.; Hanemann, T.; Szabo, D. V. Electrochemical performance of tin-based nano-composite electrodes using a vinylene carbonate-containing electrolyte for Li-ion cells. 2014. Journal of power sources, 263. doi: $10.5445 / I R / 110096754$

Zitierung der Originalveröffentlichung:

Kilibarda, G.; Schlabach, S.; Winkler, V.; Bruns, M.; Hanemann, T.; Szabo, D. V. Electrochemical performance of tin-based nano-composite electrodes using a vinylene carbonate-containing electrolyte for Li-ion cells.

2014. Journal of power sources, 263 (October), 145-153.

doi:10.1016/j.jpowsour.2014.04.030 